\title{
Analysis of the Power Balance In the Cells of a Multilevel Cascaded H-Bridge Converter
}

\author{
S. Vazquez, Member, IEEE, J. I. Leon, Member, IEEE, J. M. Carrasco, Member, IEEE, L. G. Franquelo, Fellow, \\ IEEE E. Galvan, Member, IEEE, M. Reyes, Member, IEEE, J.A. Sanchez and E. Dominguez, Member, IEEE
}

\begin{abstract}
Multilevel cascaded H-Bridge converters (CHB) have been presented as a good solution for high power applications. In this way, several control and modulation techniques have been proposed for this power converter topology. In this paper the steady state power balance in the cells of the single phase two cell CHB is studied. The capability to be supplied with active power from the grid or to deliver active power to the grid in each cell is analyzed according to the dc-link voltages and the desired ac output voltage value. Limits of the maximum and minimum input active power for stable operation of the CHB are addressed. Simulation results are shown to validate the presented analysis.
\end{abstract}

\section{INTRODUCTION}

M ULTILEVEL converters have turned into a mature technology that has increase its use in last years [1]-[3]. Among the multilevel converter topologies the cascaded $\mathrm{H}$ bridge converters (CHB) were firstly presented in 1975, [4], [5]. Since then, the researches have paid attention in this topology because it presents several advantages compared with other multilevel converter topologies in terms of modularity, simplicity and number of levels with minimum number of power semiconductors [6]-[8].

The CHB has been used to develop different applications such as synchronous rectifiers, inverters, Statcoms, active filters, renewable energy integration systems, motor drives, etc [9]-[16]. Besides, specific control strategies and modulation techniques, associated with those applications, have been designed for this converter topology [17]-[22]. As each dc-link is independent, when the CHB converter is used as a synchronous rectifier, it is possible to connect loads with several values to each dc-link. Besides, each dc-link can be controlled to a different dc voltage level providing a high degree of freedom. When two or more dc voltage values are needed, although it is possible to use independent two-level converters, the CHB converter provides some extra benefits. It has a lower input current harmonic content, thus a lower smoothing inductor value can be used. Besides, when independent two-level converters are used, it is necessary to put

Manuscript received March 13, 2009. Accepted for publication September 26, 2009. This work was supported by the Spanish Science and Education Ministry under project TEC2007-61879. Copyright (c) 2009 IEEE. Personal use of this material is permitted. However, permission to use this material for any other purposes must be obtained from the IEEE by sending a request to pubs-permissions@ieee.org. S. Vazquez, J. I. Leon, J. M. Carrasco, L. G. Franquelo, E. Galvan, M. Reyes, J.A. Sanchez and E. Dominguez are with the Electronic Engineering Department, University of Seville (Spain), (e-mail: svazquez@gte.esi.us.es). an smoothing inductor for each converter. Therefore the CHB provides reduction in overall volume, weight and economical cost. For these reasons, the CHB topology is very suitable when two or more dc voltage levels are needed. However, the converter operation has to be taken into account in the design process. Due to the fact that every cell share the same input ac current, the loading condition of each cell affects to the behavior of the overall system.

In this paper the steady state power balance in the cells of a single-phase two-cell multilevel cascaded H-bridge power converter (2C-CHB) and the grid is analyzed. In section II a brief description of the 2C-CHB topology is presented. Then in section III the steady state power balance in the cells of the $2 \mathrm{C}-\mathrm{CHB}$ is studied. The capability to be supplied with active power from the grid or to deliver active power to the grid in each cell is analyzed according to the dc-link voltages and the desired ac output voltage value, addressing the limits of the maximum and minimum loads for stable operation of the 2CCHB. In section IV a brief description of the system controller is introduced. Finally in sections V and VI, simulation results validating the presented analysis and final conclusions are stated.

\section{SYSTEM DESCRIPTION}

A single-phase two-cell multilevel cascaded H-bridge power converter (2C-CHB) is depicted in Fig. 1. The system is connected to the grid through a smoothing inductor $L$. Load behavior is considered by using current sources $i_{L 1}$ and $i_{L 2}$ connected to each dc-link capacitor, $C_{1}$ and $C_{2}$ respectively. The system parameters and variables are described in Table I, where the continuous control signals $\delta_{1}$ and $\delta_{2}$, represent the switching functions.

The equations that describe the 2C-CHB behavior are well known and they have been reported previously [23].

$$
\begin{gathered}
v_{m 1}=\delta_{1} v_{d c 1} \quad ; \quad p_{1}=v_{d c 1} i_{L 1} \\
v_{m 2}=\delta_{2} v_{d c 2} \quad ; \quad p_{2}=v_{d c 2} i_{L 2} \\
p_{t}=p_{1}+p_{2} \\
V_{s}=L \frac{d I_{s}}{d t}+v_{m 1}+v_{m 2} \\
v_{m 1} I_{s}=C_{1} \frac{d}{d t}\left(\frac{v_{d c 1}^{2}}{2}\right)+p_{1} \\
v_{m 2} I_{s}=C_{2} \frac{d}{d t}\left(\frac{v_{d c 2}^{2}}{2}\right)+p_{2}
\end{gathered}
$$


TABLE I

SYSTEM VARIABLES.

\begin{tabular}{cc}
\hline \hline Parameter & Description \\
\hline$L$ & Smoothing inductor \\
$C_{1}, C_{2}$ & Dc-link capacitors \\
$i_{L 1}, i_{L 2}$ & Load currents \\
$I_{s}$ & Grid current \\
$V_{s}$ & Grid voltage \\
$v_{d c 1}, v_{d c 2}$ & Dc-link voltages \\
$V_{a b}$ & Converter output voltage \\
$v_{m 1}, v_{m 2}$ & Cell output voltages \\
$\delta_{1}, \delta_{2} \epsilon[-1,1]$ & Control signals \\
$p_{t}$ & Converter input instantaneous power \\
\hline \hline
\end{tabular}

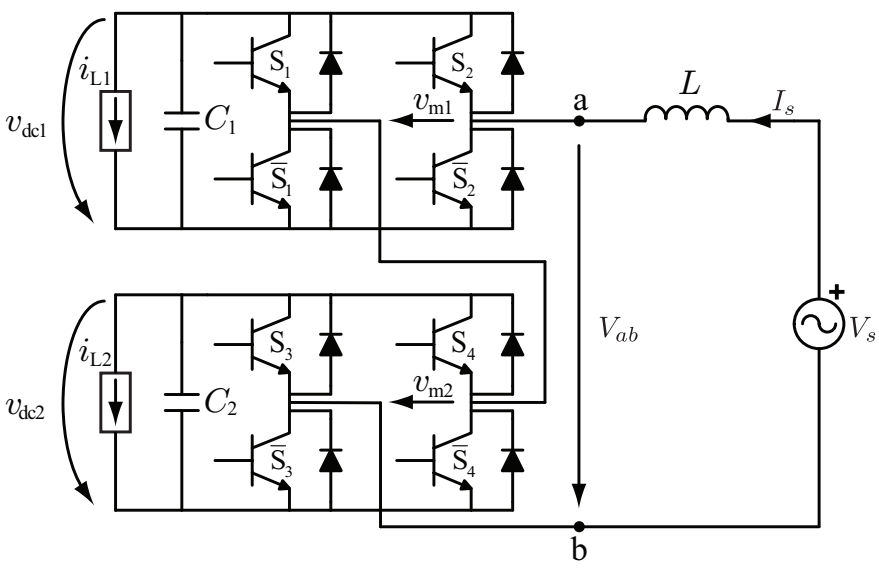

Fig. 1. Two-cell single-phase CHB power converter.

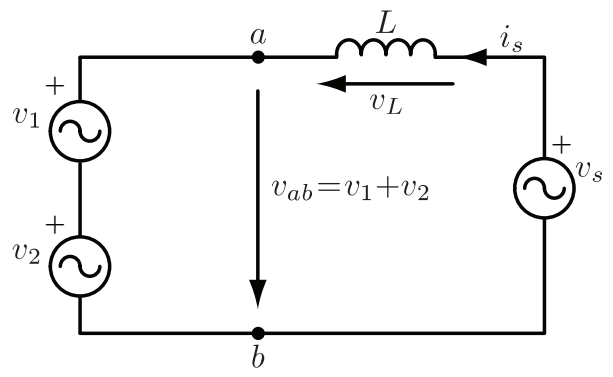

Fig. 2. 2C-CHB equivalent circuit.

The behavior of the 2C-CHB is characterized by the inductor current dynamic (4) and dc-link capacitor voltage dynamic in each cell (5)-(6). In these equations, signals $v_{m 1}$ and $v_{m 2}$ represent the output voltage of each cell. These voltages depend on the dc-link voltage and the control signal values in each cell. Besides, signals $p_{1}$ and $p_{2}$ are the instantaneous power demanded or delivered by the current sources connected to each cell respectively.

To analyze the steady state power balance in the cells of a cascade converter, the power converter equivalent circuit shown in Fig. 2 is used. In this representation, the cells have been replaced by voltage sources with values $v_{1}$ and $v_{2}$, equal to the RMS values of the fundamental harmonic of the voltages modulated by the cells, $v_{m 1,1}$ and $v_{m 2,1}$ respectively. Besides, the RMS values of the fundamental harmonic of the output phase voltage $\left(v_{a b}\right)$, grid voltage $\left(v_{s}\right)$ and grid current $\left(i_{s}\right)$ are considered in the equivalent circuit.

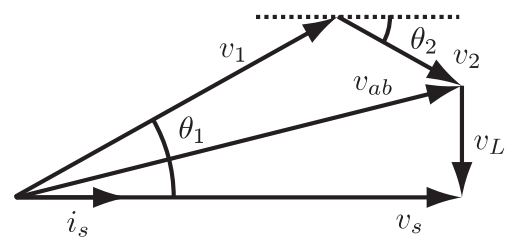

Fig. 3. 2C-CHB phasorial diagram of voltages and current.

$$
x_{y}=\sqrt{\frac{1}{T} \int_{0}^{T} X_{y, 1}^{2} d t}
$$

The RMS values can be calculated from the fundamental harmonic value of each variable using (7), where $x_{y}$ represents the RMS and $X_{y, 1}$ represents the fundamental harmonic.

$$
\begin{aligned}
& P_{y}=v_{y} i_{y} \cos \theta_{y} \\
& Q_{y}=v_{y} i_{y} \sin \theta_{y} .
\end{aligned}
$$

The equivalent circuit is composed by sinusoidal voltage sources and passive components. As a consequence it is possible to analyze it using conventional active and reactive power definitions under sinusoidal conditions for single-phase systems [24]- [25].

In equations (8) and (9) $v_{y}$ and $i_{y}$ are the RMS values of the voltage and the current respectively and $\theta_{y}$ represents the shift angle between them. Besides, $P_{y}$ is the active power which is equal to the mean value of the instantaneous power $p_{y}$ and $Q_{y}$ is the reactive power.

\section{POWER BALANCE ANALYSIS}

The sign of the active power of each cell depends on the shift angle between the current $i_{s}$ and the output voltage in the cell $v_{i, i=1,2}$. This can be analyzed using the phasorial diagram of the 2C-CHB equivalent circuit represented in Fig. 3, where the RMS values of the converter main magnitudes are plotted. In the analysis it is assumed that, $v_{a b}$ is calculated in such a way that $i_{s}$ is in phase with $v_{s}$. Other solutions can be considered, however the same active power has to be supplied by the grid to the cells or delivered from the cells to the grid. The only difference is the shift angle between the input current and the grid voltage, leading to a reactive power exchange between the grid and the converter. Therefore the conclusions from the presented analysis are still valid. In these phasorial diagrams, it is important to show the maximum output voltages in RMS of each H-bridge which can be calculated as

$$
\begin{aligned}
& v_{c 1}=\frac{4}{\pi \sqrt{2}} v_{d c 1} \\
& v_{c 2}=\frac{4}{\pi \sqrt{2}} v_{d c 2} .
\end{aligned}
$$

The capability to be supplied with active power from the grid or to deliver active power to the grid in each cell depends on the value of the capacitor voltage in the cell, and the voltage that should be modulated by the 2C-CHB. In what follows, the three possible cases are described and in all cases, it is assumed that $v_{a b}$ can be modulated by the converter, i.e:

$$
v_{c 1}+v_{c 2} \geq v_{a b} .
$$




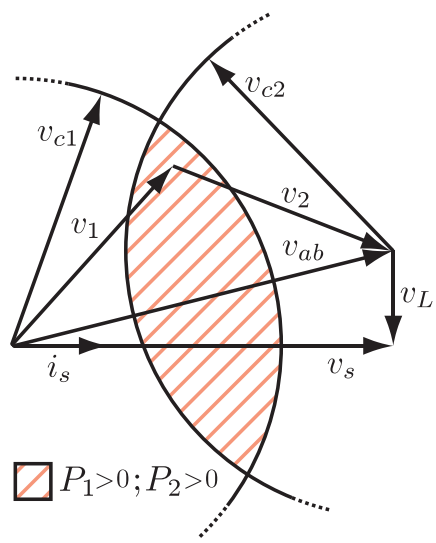

Fig. 4. Stable control area when $v_{c 1} \leq v_{a b}$ and $v_{c 2} \leq v_{a b}$.

A. $v_{c 1} \leq v_{a b}$ and $v_{c 2} \leq v_{a b}$

In this case it is necessary to use both cells to generate the output voltage $v_{a b}$. Fig. 4 shows in a red marked area the possible points to achieve the desired output voltage. Any point outside of this region make the system unstable because the output voltage can not be modulated with those values of the dc-link capacitor voltages. In addition, as it is shown in the figure, the projection of $v_{1}$ over $i_{s}$ is always positive and the same occurs for $v_{2}$, as a consequence the active power in both cells are positive values, meaning that the grid supplies active power to both cells simultaneously Moreover, it is not possible to find a point where the grid supplies active power to once cell and at the same time the other cell delivers active power to the grid. In addition, this situation means that it is not possible to have the grid supplying active power only to one cell or to have only one cell delivering active power to the grid On the other hand, it can be observed that the reactive power exchanged with the inductor is supplied by the cells. There is no restriction to the reactive power sign contributed by each cell. This means that the reactive power in each cell can be different, even in one cell the reactive power can have capacitive nature meanwhile in the other it has inductive nature.

In Fig. 5 it is shown that, for a given total amount of active power supplied by the grid to the the converter, the power delivered to each cell has to be between a minimum and a maximum value to achieve a stable operation. Fig. 5a shows the minimum active power that has to be supplied to cell 1 . This value corresponds with the minimum reachable length of the projection of $v_{1}$ over $i_{s}$, represented in the figure with $v_{1 p}^{\text {min }}$. As the total amount of active power is fixed, this value is related with the maximum active power that can be delivered to cell 2, shown in Fig. 5a as $v_{2 p}^{\max }$, which is the maximum reachable length of the projection of $v_{2}$ over $i_{s}$. In the same way, the values for the maximum active power that can be supplied in cell $1, v_{1 p}^{\max }$, and the minimum active power that has to be delivered to cell $2, v_{2 p}^{\min }$, can be defined. These values are represented in Fig. $5 b$.
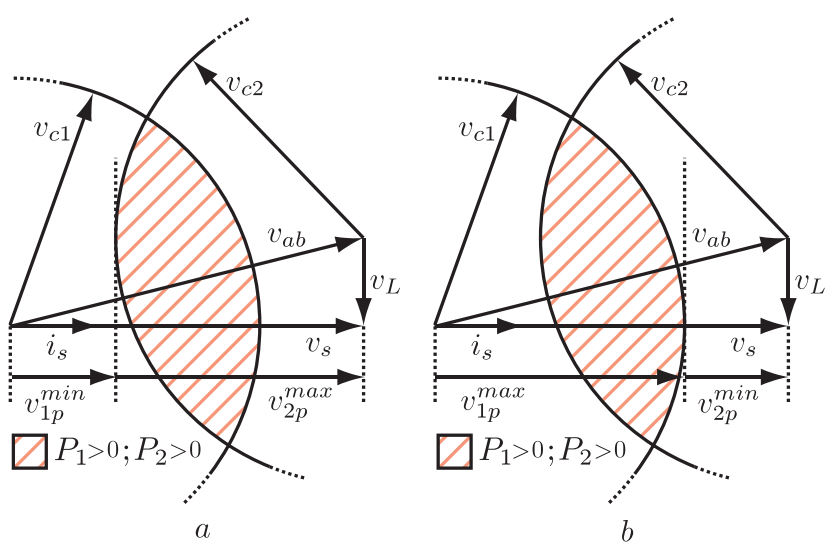

Fig. 5. Maximum and minimum active power limits when $v_{c 1} \leq v_{a b}$ and $v_{c 2} \leq v_{a b}$.

B. $v_{c 1}>v_{a b}$ and $v_{c 2} \leq v_{a b}$

In this case the desired output voltage can be achieved using both cells or just using the cell with the higher dc voltage. This allows two possible power balance situations in the cells. In Fig. 6 the marked red area represents the points where both cells are supplied with active power from the grid, while the marked green area shows the points where the first cell is supplied with active power from the grid meanwhile the second cell delivers active power to the grid. As in section III-A, the reactive power is exchanged between the inductor and the cells without restrictions in the reactive power sign contributed by each one.

Fig. 6a shows a possible solution with both cells supplied with active power from the grid and Fig. $6 \mathrm{~b}$ shows a possible solution when the first cell is supplied from the grid meanwhile the second cell delivers active power to the grid. It is worth noting that when $v_{c 1}>v_{a b}$ and $v_{c 2} \leq v_{a b}$, if the total active power supplied to the converter from the grid is positive then only the second cell active power can be negative meanwhile the first cell active power is positive, and it is not possible to have a negative active power in the first cell meanwhile the second cell has a positive active power value.

Fig. 7 shows the limits for the maximum and minimum active power values allowed in the cells to achieve a stable operation when the total amount of active power supplied from the grid to the converter is fixed. Two different power balance situations can be clearly identified.

The first one can be considered as the conventional operation of the converter and it is shown in Fig. 7a. In this case both cells are supplied from the grid, as a consequence a minimum active power has to be supplied to cell 1 from the grid, this value corresponds with the minimum reachable length of the projection of $v_{1}$ over $i_{s}$, represented in the figure with $v_{1 p}^{\min }$. Associated with this value is $v_{2 p}^{\max }$, which is the maximum reachable length of the projection of $v_{2}$ over $i_{s}$ and represents the maximum active power that can be supplied to cell 2.

The second power balance situation, represented in Fig. 7b, implies that the active power in each cell have different sign. Thus the cell with the higher dc voltage is supplied from the grid meanwhile the other cell is delivering active power to 

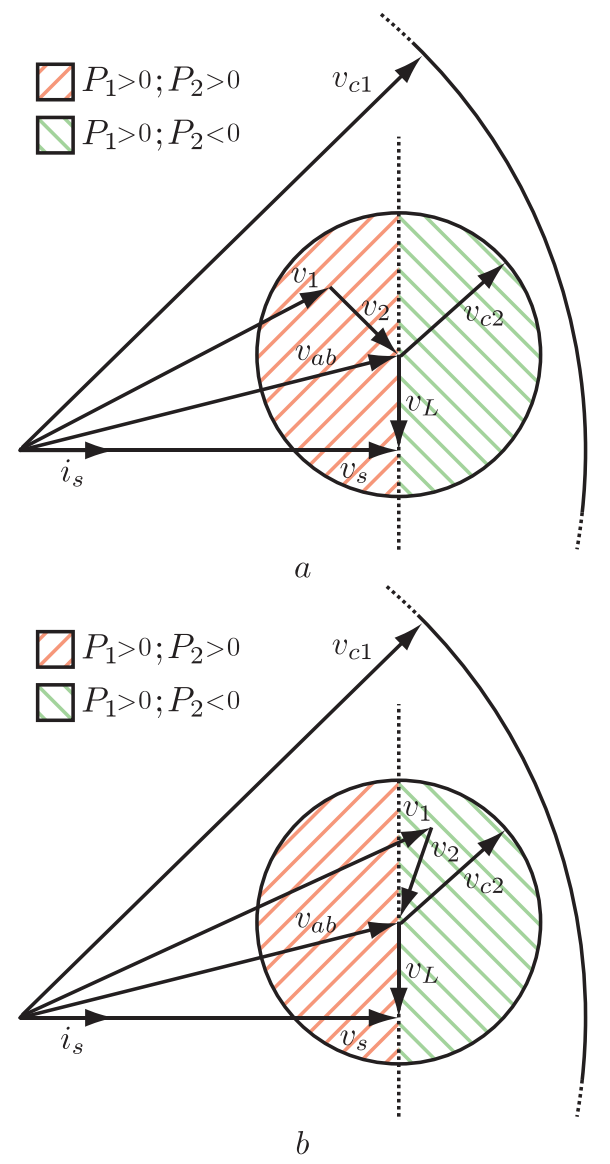

Fig. 6. Stable control area when $v_{c 1}>v_{a b}$ and $v_{c 2} \leq v_{a b}$. From top to bottom: Possible solution with: a) $P_{1}>0$ and $P_{2}>0$. b) $P_{1}>0$ and $P_{2}<0$.

the grid. Under this situation, the values for the maximum active power that can be delivered to cell $1, v_{1 p}^{\max }$, and the minimum active power that has to be supplied to cell $2, v_{2 p}^{\min }$, can be defined. In Fig. $7 \mathrm{~b}$ it can be noticed that $v_{2 p}^{\min }$ has opposite direction than $i_{s}$, so the second cell is delivering active power. Besides, the maximum active power supplied to cell 1 is higher than the total amount of active power delivered from the grid. This means that the active power delivered from the second cell is going into the first cell.

\section{C. $v_{c 1}>v_{a b}$ and $v_{c 2}>v_{a b}$}

In this case the output voltage can be modulated using both cells or just using one of them. As a consequence three possible power balance situations in the cells are under concern. In the marked red area of Fig. 8, both cells are supplied simultaneously with active power from the grid whereas the marked green area shows the set of points where the first cell is supplied with active power from the grid meanwhile the second cell delivers active power to the grid. In opposite, the marked light blue area represents the set of points where the first cell delivers active power to the grid meanwhile the second cell is supplied with active power from the grid. Again, the reactive power is exchanged between the smoothing inductor and the cells without restrictions in the sign of the reactive power of each cell.

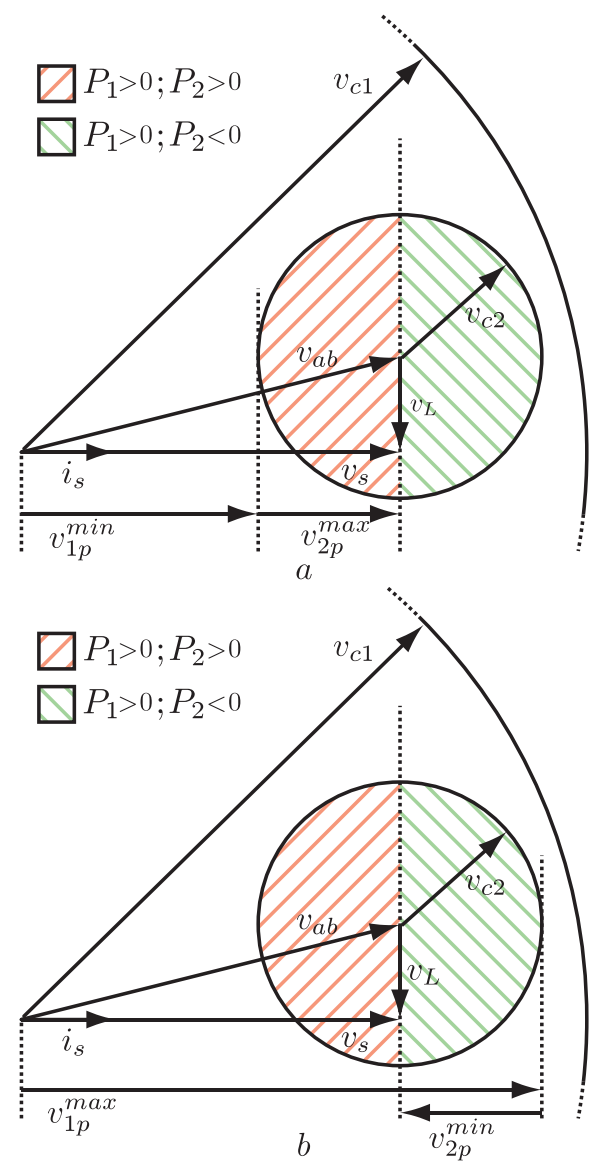

Fig. 7. Maximum and minimum active power limits when $v_{c 1}>v_{a b}$ and $v_{c 2} \leq v_{a b}$.

Fig. 8 shows three possible solutions, one for each power balance situation under concern. Fig. 8a shows the conventional operation, where both cells are supplied with active power from the grid. Fig. 8 b represents the converter operation when the first cell is supplied from the grid meanwhile the second cell delivers active power to the grid. Finally, Fig. 8c shows a solution with the first cell delivering active power to the grid meanwhile the second cell is supplied with active power from the grid. It can be noticed that when $v_{c 1}>v_{a b}$ and $v_{c 2}>v_{a b}$, although the total active power supplied to the converter from the grid is positive it is possible that any one cell delivers active power to the grid meanwhile the other one is supplied with active power from the grid.

When the maximum and minimum limits of the active power consumed or injected by the loads connected to the cells are analyzed, similar conclusions to those presented in section III-B, when the power balance through each cell have different sign, are found. In Fig. 9 are shown the maximum active power that can be supplied and the minimum active power values that have to be deliver to each cell to achieve a stable operation, for a given total amount of active power consumed by the loads connected to the converter. Under this situation, the minimum active power that has to be supplied in each cell is negative, thus the cell is delivering active power. Meanwhile the maximum active power that can be consumed by the loads connected to the cell is higher than the total 

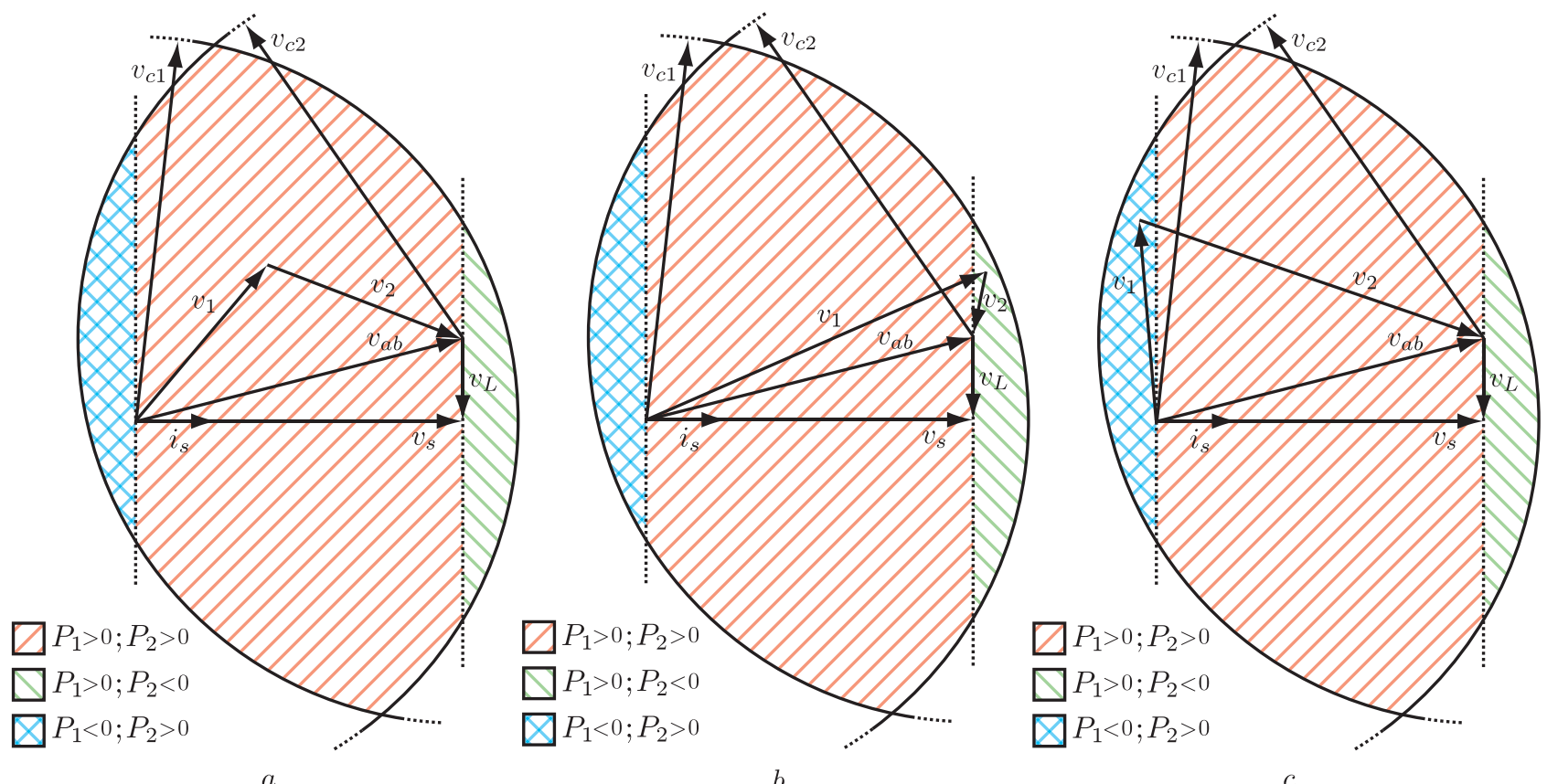

$b$

$c$

Fig. 8. Stable control area when $v_{c 1}>v_{a b}$ and $v_{c 2}>v_{a b}$. From left to right: Possible solution with: a) $P_{1}>0$ and $P_{2}>0$. b) $P_{1}>0$ and $P_{2}<0$. c) $P_{1}<0$ and $P_{2}>0$.

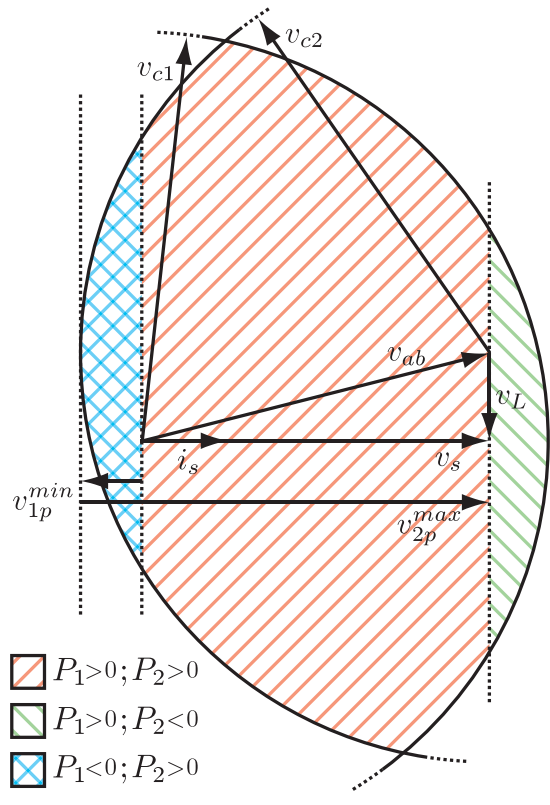

$a$

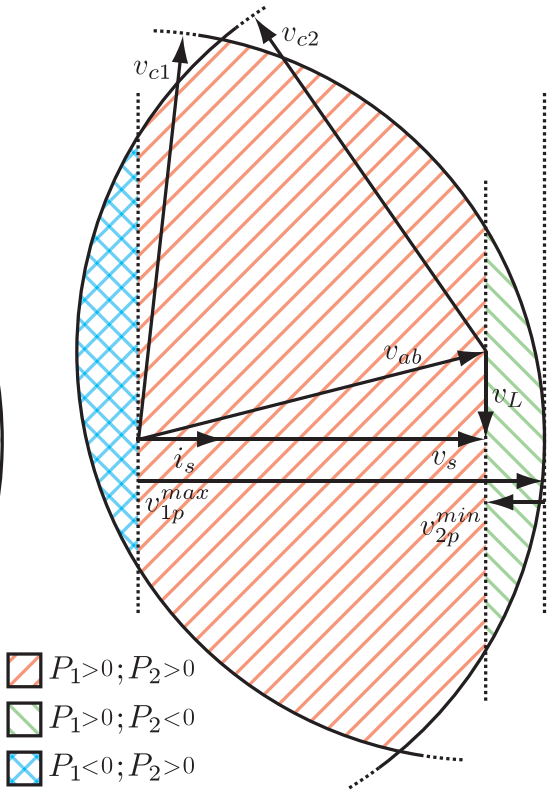

$b$

Fig. 9. Maximum and minimum active power limits when $v_{c 1}>v_{a b}$ and $v_{c 2}>v_{a b}$.

active power supplied to the converter, thus part of the energy consumed in this cell comes from the other cell and not from the grid.

\section{SYSTEM CONTROLLER}

The system controller design has to take under concern the control objectives in the $2 \mathrm{C}-\mathrm{CHB}$ connected to the grid. These control objectives are:

(i) Regulate the capacitor voltages to the desired values $V_{d c 1}^{*}$ and $V_{d c 2}^{*}$ (ii) Achieve grid current with high quality harmonic content and maintain the power factor as close to unity as possible.

In this paper the proposed controller in [26] is used. This controller consists of three control loops and is summarized in the block diagram represented in Fig. 10, where $k_{p 1}, k_{i 1}, k_{p 2}$, $k_{i 2}, k_{p c 1}, k_{p c 2}, k_{r}$ and $K$ are design positive constant. Besides, in [26], it is pointed out that multiple solutions can exist to achieve the same active power distribution in the cells, only the reactive power contributed by each cell changes, as it is shown in Fig. 11 for the cases presented in sections III-A and III-B. 


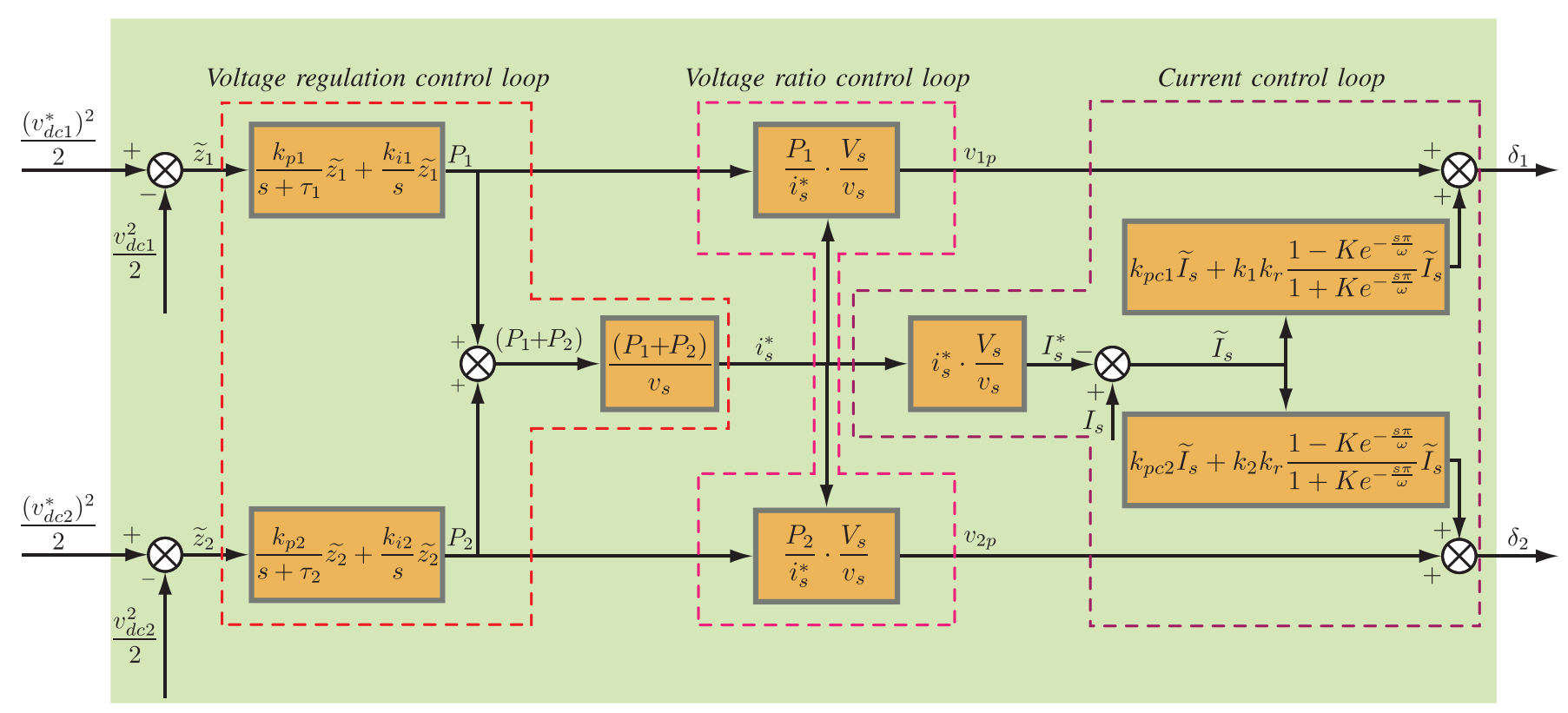

Fig. 10. Block diagram of the system controller.
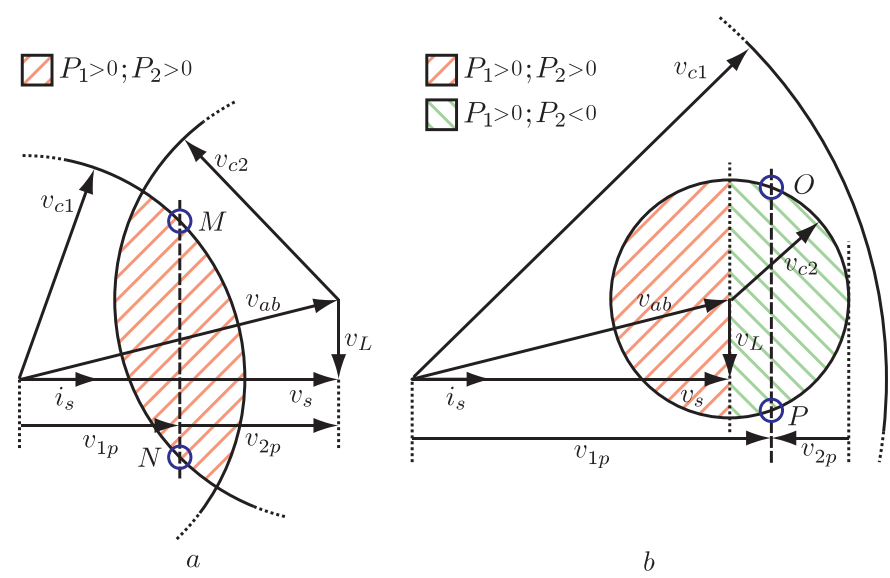

Fig. 11. Set of possible solutions for a particular active power distribution. From left to right: a) $v_{c 1} \leq v_{a b}$ and $v_{c 2} \leq v_{a b}$. b) $v_{c 1}>v_{a b}$ and $v_{c 2} \leq v_{a b}$.

In Fig. 11a, all the points located in the segment between the points MN lead to the same active power consumption in each cell. Only the reactive power contribution changes. Same conclusion can be reached for the points located in the segment between the points OP of Fig. 11b. In the proposed controller, the reactive power contribution of each cell is defined by the values of the design constants $k_{1}$ and $k_{2}$, which must satisfy

$$
k_{1}+k_{2}=1
$$

\section{Simulation RESUlts}

In this section, simulation results are shown to validate the analysis presented in section III. For this purpose a singlephase two-cell multilevel cascaded H-bridge converter prototype has been used. The electric parameters of the prototype are summarized in Table II. The proposed control of
TABLE II

ELECTRIC PARAMETERS.

\begin{tabular}{cc}
\hline \hline Parameter & Description \\
\hline RMS grid voltage $\left(v_{s}\right)$ & $230 \mathrm{~V}$ \\
Grid frequency $(f)$ & $50 \mathrm{~Hz}$ \\
Smoothing inductance $(L)$ & $3 \mathrm{mH}$ \\
DC-Link capacitors $\left(C_{1}, C_{2}\right)$ & $2200 \mu \mathrm{F}$ \\
Switching frequency $\left(f_{s w}\right)$ & $10 \mathrm{kHz}$ \\
Sampling frequency $\left(f_{s}\right)$ & $10 \mathrm{kHz}$ \\
\hline \hline
\end{tabular}

TABLE III

CONTROL CONSTANTS

\begin{tabular}{cc}
\hline \hline Parameter & Description \\
\hline$k_{p 1}, k_{p 2}$ & 0.05 \\
$k_{i 1}, k_{i 2}$ & $0.5 T_{s w}$ \\
$k_{p c 1}, k_{p c 2}$ & 6 \\
$k_{r}$ & 1.8 \\
$K$ & 0.9 \\
$k_{1}, k_{2}$ & 0.5 \\
\hline \hline
\end{tabular}

section IV has several design constants, which have been adjusted experimentally to achieve a good behavior of the proposed controller. These constant values are summarized in Table III. To assess the presented analysis, three different experiments are described. The first one shows the converter operation in the stable region as described in subsection III-A while the second experiment shows the prototype behavior when the loading condition leads outside this stable operation region. Finally, an experiment showing the stable converter operation with both cells having opposite power balance sign, as presented in subsection III-B, is analyzed.

\section{A. Stable operation with $v_{c 1} \leq v_{a b}$ and $v_{c 2} \leq v_{a b}$}

In this case, both cells have to be supplied or to deliver active power from the grid simultaneously. To illustrate this 


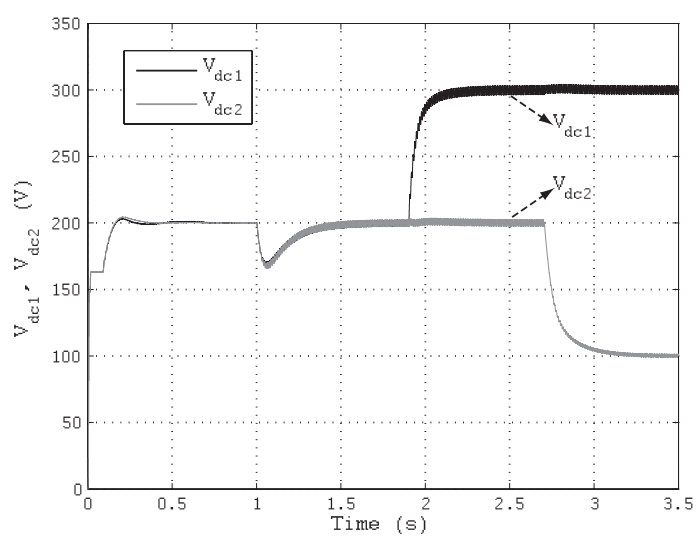

Fig. 12. Evolution in time of dc voltages.

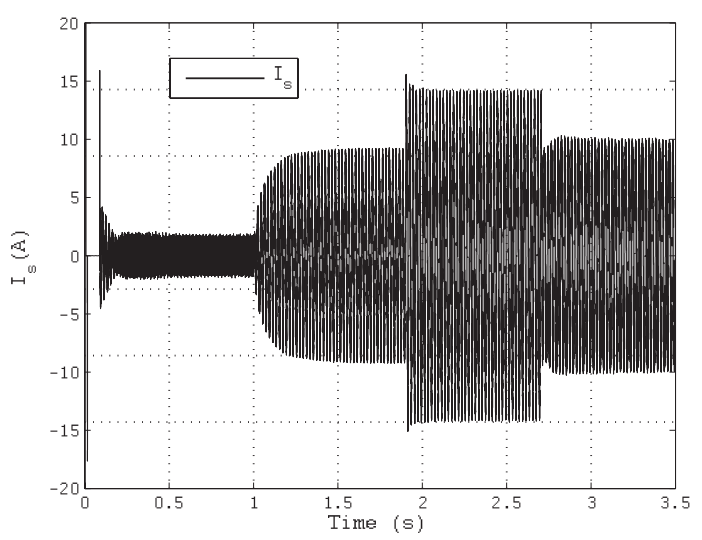

Fig. 13. Evolution in time of grid current.

operation a resistor of $60 \Omega$ is connected to each dc-link as a load. Several dc voltage step references are applied to show the behavior of the 2C-CHB. Initially the dc voltage commands are set to $200 \mathrm{~V}$. When the actual dc voltages achieve their references the loads are connected. Approximately two seconds later the voltage command for the first cell is changed to $300 \mathrm{~V}$ and then, after one second, a new reference for the second cell of $100 \mathrm{~V}$ is established.

Fig. 12 shows the evolution in time of $v_{d c 1}$ and $v_{d c 2}$, and Fig. 13 the input current in the same period of time. It can be noticed that the dc output voltage references are achieved without difficulties. Besides $I_{s}$ grows or decreases in accordance with the output load value variations. Additionally, the input current is almost in phase with the input voltage and presents a low total harmonic distortion (THD), this can be observed in Fig. 14 where a detail of $V_{s}$ and $I_{s}$ is shown. This input current has a power factor (PF) of 0.99 and a THD of $2.5 \%$. This THD value has been calculated up to the $50^{t h}$ harmonic order.

\section{B. Unstable operation with $v_{c 1} \leq v_{a b}$ and $v_{c 2} \leq v_{a b}$}

In this section it is shown the behavior of the 2C-CHB converter when is operated in a point outside the stable region. As has been shown in section III-A, for a fixed total amount of active power exist a minimum active power values that have to be consumed by the loads connected in each cell and

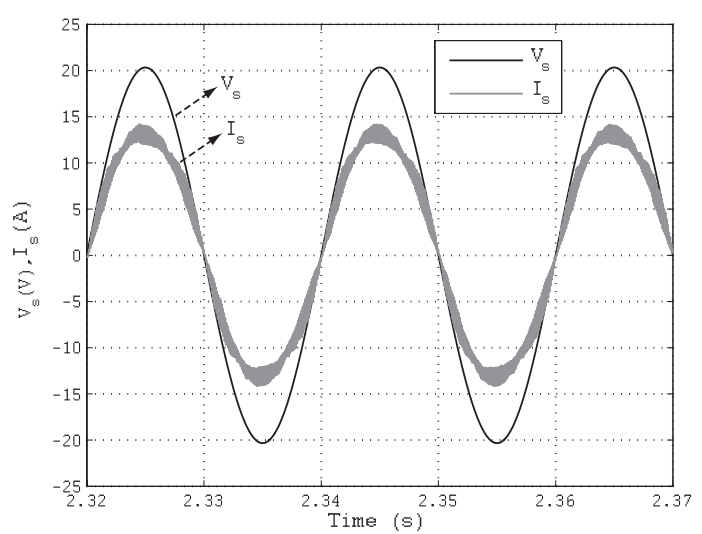

Fig. 14. Detail of grid voltage and current.

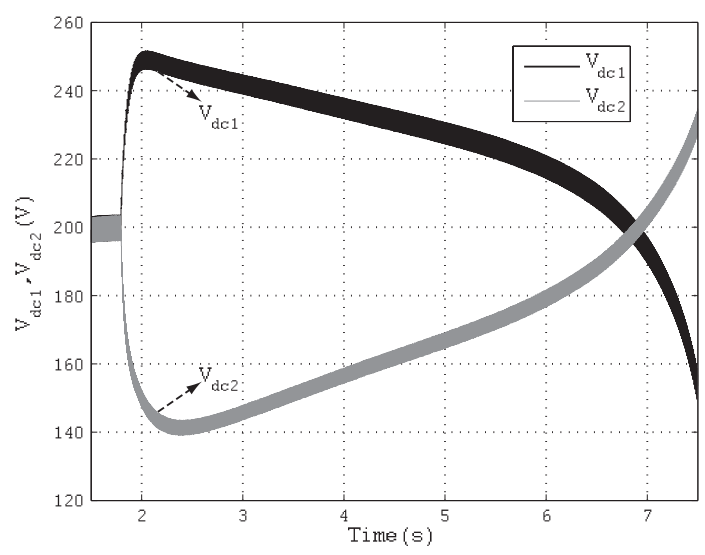

Fig. 15. Evolution in time of dc voltages.

a maximum active power values that can be supplied to the cells. In this experiment, the output dc voltage commands are established to $200 \mathrm{~V}$ and the total active power consumed by the converter is set to $2 \mathrm{~kW}$. The minimum and maximum active power values under these working conditions can be calculated using equations (14) to (17) and are summarized in Table IV. Initially the converter is operated with a load located inside the stable region. For this purpose two resistors of $40 \Omega$ are connected to the cells, consuming $1 \mathrm{~kW}$ in each cell. Then a load step is applied to the converter in such a way that the converter goes to an unstable point. To achieve this condition, a resistor of $100 \Omega$ is connected in the first cell and $25 \Omega$ to the second cell, drawing $1.6 \mathrm{~kW}$ and $0.4 \mathrm{~kW}$ respectively.

$$
\begin{aligned}
P_{1}^{\max } & =\frac{v_{1 p}^{\max }}{v_{s}} P_{t} \\
P_{1}^{\min } & =\frac{\left(v_{s}-v_{2 p}^{\max }\right)}{v_{s}} P_{t} \\
P_{2}^{\max } & =\frac{v_{2 p}^{\max }}{v_{s}} P_{t} \\
P_{2}^{\text {min }} & =\frac{\left(v_{s}-v_{1 p}^{\max }\right)}{v_{s}} P_{t}
\end{aligned}
$$

Fig. 15 shows the behavior of the dc voltages and Fig. 16 the evolution of the input current. It can be noticed that for the first load configuration the converter achieves a stable 


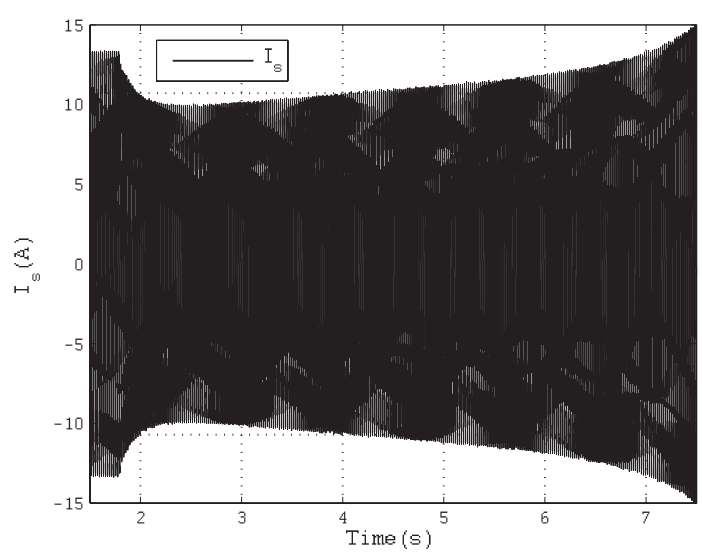

Fig. 16. Evolution in time of grid current.

TABLE IV

MAXIMUM AND MINIMUM ACTIVE POWER VALUES.

\begin{tabular}{cc}
\hline \hline Parameter & Description \\
\hline$P_{1}^{\max }, P_{2}^{\max }$ & $1566 \mathrm{~W}$ \\
$P_{1}^{\text {min }}, P_{2}^{\text {min }}$ & $434 \mathrm{~W}$ \\
\hline \hline
\end{tabular}

operation, the dc voltages are stable in the reference commands and the input current is established in agreement with the output load. When the load step is applied, the converter tries to follow the references however, as it is working outside the stable region, it is not possible to achieve the commands and the dc voltages change without control. Finally the converter has to be stopped to avoid a malfunction caused by the input current or by a high output voltage value.

\section{Stable operation with $v_{c 1}>v_{a b}$ and $v_{c 2} \leq v_{a b}$}

When $v_{c 1}>v_{a b}$ and $v_{c 2} \leq v_{a b}$, the stable region can be split in two areas depending on the cells power balance. In this experiment, the behavior of the $2 \mathrm{C}-\mathrm{CHB}$ converter working in both areas is explored. To develop the test, the following steps are applied. In the beginning both cells are controlled to $200 \mathrm{~V}$ and a resistor of $100 \Omega$ is connected to each cell. When the steady state is achieved, the first cell command is changed to $400 \mathrm{~V}$, thus the converter load is consuming $2 \mathrm{~kW}$ with both cells supplied with active power from the grid. Then, after one second, a current source is connected to the second cell to supply power from the cell to the grid. For this purpose, the source injects a current of $1.7 \mathrm{~A}$ so the final active power value supplied to the converter from the grid is $1.7 \mathrm{~kW}$ but the first cell is supplied from the grid meanwhile the second cell delivers active power to the grid. Fig. 17 shows the dc voltages change along the time. It can be noticed that, when the current source is connected at $5.5 \mathrm{~s}, v_{c 1}$ and $v_{c 2}$ values increase, due to the active power delivered by the second cell. However the controller evacuates this power achieving the voltage reference commands. When grid current is observed (Fig. 18), it can be appreciated that current amplitude decreases when active power is supplied from the second cell, so there is an energy transfer from the second cell to the first cell.

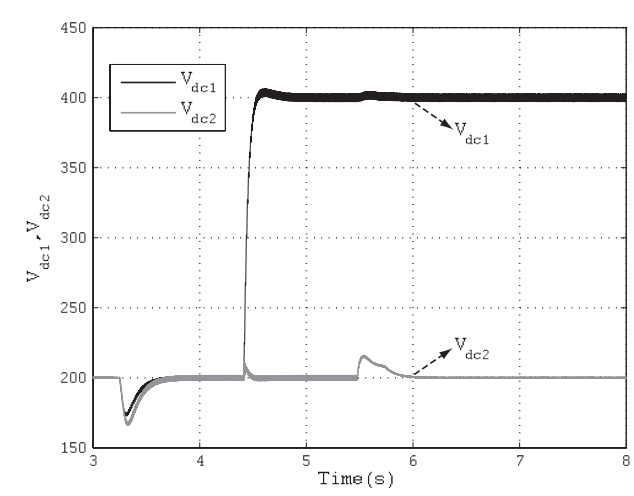

Fig. 17. Evolution in time of de voltages.

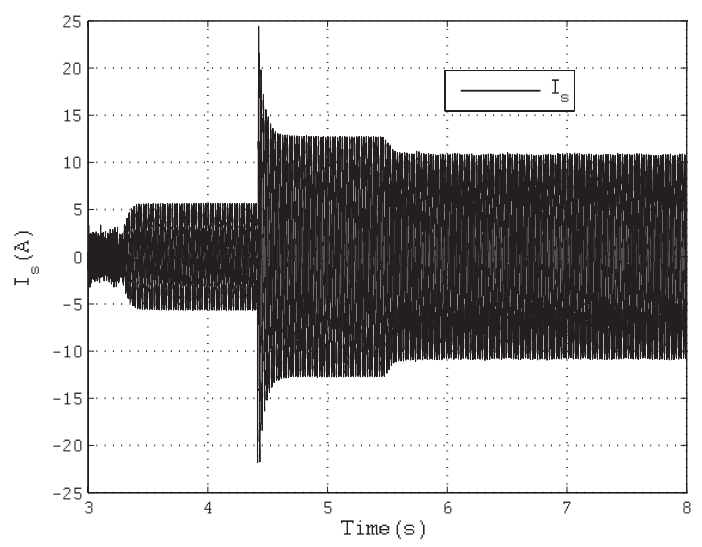

Fig. 18. Evolution in time of grid current.

\section{CONCLUSIONS}

The cascaded multilevel H-bridge power converter (CHB) is a suitable topology to be used when two or more independent dc voltage values are needed in a synchronous rectifier or backto-back application. However some criteria have to be taken into account to achieve a stable converter operation. In this paper, the power balance limits in the cells of a single-phase twocell multilevel cascaded H-bridge power converter (2C-CHB) are addressed. These limits depend on the dc-link voltage values. It is shown that under certain conditions, it is possible to have opposite sign active power values simultaneously in both cells. Besides, to have a stable operation it is necessary to ensure that, for a total amount of active power supplied to the $2 \mathrm{C}-\mathrm{CHB}$, both cells loads are between the maximum and minimum allowed. Finally, simulation results are introduced validating that the presented analysis is an appropriate tool to establish the design criteria for the $2 \mathrm{C}-\mathrm{CHB}$ synchronous rectifier or back-to-back application.

\section{REFERENCES}

[1] J. Rodriguez, S. Bernet, B. Wu, J. O. Pontt and S. Kouro, "Multilevel Voltage-Source-Converter Topologies for Industrial Medium-Voltage Drives," IEEE Transactions on Industrial Electronics, vol. 54, no. 6, pp. 2930-2945, December 2007

[2] L. G. Franquelo, J. Rodriguez, J. I. Leon, S. Kouro, R. Portillo and M. M. Prats, "The age of multilevel converters arrives," IEEE Industrial Electronics Magazine, vol. 2, no. 2, pp. 28-39, June 2008. 
[3] D. Krug, S. Bernet, S. S. Fazel, K. Jalili and M. Malinowski, "Comparison of 2.3-kV Medium-Voltage Multilevel Converters for Industrial Medium-Voltage Drives," IEEE Transactions on Industrial Electronics, vol. 54, no. 6, pp. 2979-2992, Dec. 2007.

[4] R. H. Baker and L. H. Bannister, Electric power converter, U.S. Patent 3867 643, Feb. 18, 1975.

[5] M. Marchesoni, M. Mazzucchelli and S. Tenconi, "A non Conventional Power Converter for Plasma Stabilization," in Power Electronics Specialist Conference 1988 (PESC'88), pp. 122-129, 11-14 April 1988.

[6] J. Rodriguez, Jih-Sheng Lai and Fang Zheng Peng, "Multilevel inverters: a survey of topologies, controls, and applications," IEEE Transactions on Industrial Electronics, Volume 49, Issue 4, pp. 724-738, August 2002.

[7] Y. Cheng, C. Qian, M.L. Crow, S. Pekarek and S. Atcitty, "A Comparison of Diode-Clamped and Cascaded Multilevel Converters for a STATCOM With Energy Storage," IEEE Transactions on Industrial Electronics, vol. 53, no. 5, pp. 1512-1521, October 2006.

[8] M.E. Ortuzar, R.E. Carmi, J.W. Dixon and L. Moran, "Voltage-source active power filter based on multilevel converter and ultracapacitor DC link," IEEE Transactions on Industrial Electronics, vol. 53, no. 2, pp. 477-485, April 2006.

[9] H. Iman-Eini, J.L. Schanen, S. Farhangi, J. Roudet, "A Modular Strategy for Control and Voltage Balancing of Cascaded H-Bridge Rectifiers," IEEE Transactions on Power Electronics, vol. 23, no 5, pp. 2428-2442, September 2008.

[10] A.J. Watson, P.W. Wheeler, J.C. Clare, "A Complete Harmonic Elimination Approach to DC Link Voltage Balancing for a Cascaded Multilevel Rectifier," IEEE Transactions on Industrial Electronics, vol 54, no 6, pp. 2946-2953, December. 2007.

[11] O. Alonso, P. Sanchis, E. Gubia, L. Marroyo, "Cascaded H-bridge multilevel converter for grid connected photovoltaic generators with independent maximum power point tracking of each solar array," in Power Electronics Specialist Conference 2003 (PESC'03), vol 2, pp 731-735, 15-19 June 2003

[12] P. Lezana, J. Rodriguez, and D. A. Oyarzun, "Cascaded multilevel inverter with regeneration capability and reduced number of switches," IEEE Transactions on Industrial Electronics, vol. 55, no. 3, pp. 10591066, March 2008.

[13] P. Lezana, C.A. Silva, J. Rodriguez, M.A. Perez, "Zero-Steady-StateError Input-Current Controller for Regenerative Multilevel Converters Based on Single-Phase Cells," IEEE Transactions on Industrial Electronics, vol 54,no 2, pp. 733-740, April 2007.

[14] R. Teodorescu,F. Blaabjerg, J.K. Pedersen, E. Cengelci, P.N. Enjeti, "Multilevel inverter by cascading industrial VSI," IEEE Transactions on Industrial Electronics, vol. 49, no 4, pp. 832-838, August 2002.

[15] J. A. Barrena, L. Marroyo, M.A.R. Vidal, J.R.T. Apraiz, "Individual Voltage Balancing Strategy for PWM Cascaded H-Bridge Converter-Based STATCOM Barrena," IEEE Transactions on Industrial Electronics, vol. 55, no 1, pp21-29, January 2008.

[16] A.M. Massoud, S.J. Finney, A.J. Cruden, B.W. William, "Three-Phase, Three-Wire, Five-Level Cascaded Shunt Active Filter for Power Conditioning, Using Two Different Space Vector Modulation Techniques," IEEE Transactions on Power Delivery, vol. 22, no 4, pp. 2349-2361, October 2007.

[17] A. Dell'Aquila, M. Liserre, V.G. Monopoli and P. Rotondo, "Overview of PI-Based Solutions for the Control of DC Buses of a Single-Phase H-Bridge Multilevel Active Rectifier," IEEE Transactions on Industry Applications, vol 44, no. 3, pp. 857-866, May-June 2008.

[18] M.A. Perez, P. Cortes and J. Rodriguez, "Predictive Control Algorithm Technique for Multilevel Asymmetric Cascaded H-Bridge Inverters," IEEE Transactions on Industrial Electronics vol. 55, no 12, pp. 4354 4361, December 2008.

[19] A. Dell'Aquila, M. Liserre, V.G. Monopoli, P. Rotondo, "Two passivitybased approaches to the control of the H-bridge-based multilevel rectifier,"; in IEEE Industrial Electronics Conference 2003 (IECON03) vol. 2, pp 1191-1196, 2-6 November 2003.

[20] D. Soto, R. Pena, "Nonlinear control strategies for cascaded multilevel STATCOMs," IEEE Transactions on Power Delivery, vol. 19, no 4, pp 1919-1927, October 2004.

[21] J. I. Leon, S. Vazquez, A. J. Watson, P. W. Wheeler, L. G. Franquelo and J. M. Carrasco, "Feed-forward Space Vector Modulation for SinglePhase Multilevel Cascaded Converters With Any DC Voltage Ratio," IEEE Transactions on Industrial Electronics, vol. 56, no. 2, pp. 315325, February 2009.

[22] C. Cecati, A. Dell'Aquila, M. Liserre, V.G. Monopoli, "Design of Hbridge multilevel active rectifier for traction systems," IEEE Transactions on Industry Applications, vol. 39, no 5, pp. 1541-1550, SeptemberOctober 2003
[23] A. Dell' Aquila, M. Liserre, V.G. Monopoli and P. Rotondo, "An EnergyBased Control for an n-H-Bridges Multilevel Active Rectifier," IEEE Transactions on Industrial Electronics, vol. 52, no. 3, pp. 670-678, June 2005.

[24] "IEEE Trial-Use Standard Definitions for the Measurement of Electric Power Quantities Under Sinusoidal, Nonsinusoidal, Balanced, or Unbalanced Conditions," IEEE Standard 1459-2000, January 2000.

[25] H. Akagi, E.H. Watanabe and M. Aredes, "Instantaneous Power Theory and Applications to Power Conditioning," Wiley, 1st Ed., 2007.

[26] S. Vazquez, J. I. Leon, J. M. Carrasco, L. G. Franquelo, E. Galvan, J. A. Sanchez and E. Dominguez, "Controller Design for a Single-Phase Two-Cell Multilevel Cascade H-bridge Converter," IEEE International Symposium on Industrial Electronics, 2008 (ISIE 2008), pp. 1-6, Cambridge, UK, June 30-July 22008.

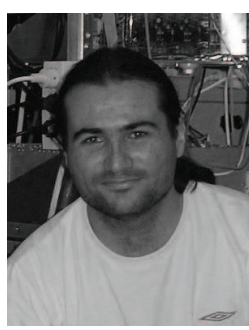

Sergio Vazquez (S'04, M'08) was born in Seville, Spain, in 1974. He received the B.S. and M.S. degrees in industrial engineering from the University of Seville (US) in 2003 and 2006, respectively. In 2002, he was with the Power Electronics Group, US, working in R\&D projects. He is currently an Assistant Professor with the Department of Electronic Engineering in the US. His research interests include electronic power systems, modeling, modulation and control of power electronic converters and power quality in renewable generation plants.

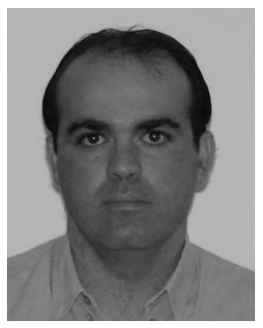

Jose I. Leon (S'04, M'07) was born in Cádiz, Spain, in 1976. He received the B.S. and M.S. and $\mathrm{PhD}$ degrees in telecommunications engineering from the University of Seville (US), Spain, in 1999, 2001 and 2006 respectively. In 2002, he joined the Power Electronics Group, US, working in R\&D projects. Currently, he is an Associate Professor with the Department of Electronic Engineering, US. His research interests include electronic power systems, modeling, modulation and control of power converters and industrial drives.

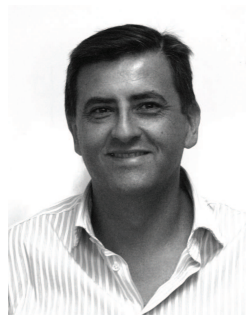

Juan M. Carrasco (M'97) was born in San Roque, Spain. He received the M.Eng. and Dr.Eng. degrees in industrial engineering from the University of Seville (US), Seville, Spain, in 1989 and 1992, respectively. From 1990 to 1995, he was an Assistant Professor with the Department of Electronic Engineering in the US where he is currently an Associate Professor. He has been working for several years in the power electronic field where he was involved in the industrial application of the design and development of power converters applied to renewable energy technologies. His current research interests are in distributed power generation and the integration of renewable energy sources.

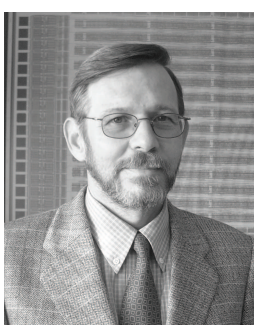

L. G. Franquelo (M'84, SM'96, F'05) was born in Málaga, Spain. He received the M.Sc. and Ph.D. degrees in electrical engineering from the University de Seville (US), Seville, Spain in 1977 and 1980 respectively. His current research interest lies on modulation techniques for multilevel inverters and its application to power electronic systems for renewable energy systems. He was the Vice-President of the Industrial Electronics Society (IES) Spanish Chapter (2002 - 2003), member at Large of the IES AdCom (2002 - 2003). He was the Vice-President for Conferences of the IES (2004 - 2007), in which he has also been a Distinguished Lecturer since 2006. He has been an Associated Editor for the IEEE Transactions on Industrial Electronics since 2007. Since January 2008 he is President Elect of IEEE Industrial Electronics Society.

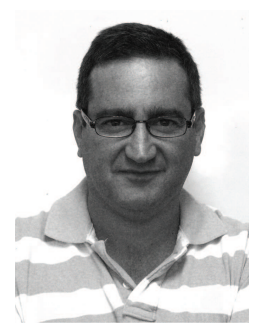

E. Galvan (M'97) was born in Aracena (Huelva), Spain, in 1964. He received the M.Sc. degree in electrical engineering and the Ph.D. degree in industrial engineering from the University of Sevilla, Sevilla, Spain, in 1991 and 1994, respectively. He is an Associate Professor of electronic engineering at the Escuela Superior de Ingenieros, Sevilla. He has been working for several years in the power electronic field where he was involved in the industrial application for the design and development of power converters applied to renewable energy technologies. His research interests include control of power converters (wind turbine applications, active filters, and electric machines). 


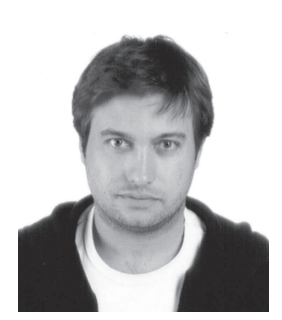

M. Reyes (S'06, M'09) was born in Seville, in Spain, in 1981. He received the B.S. and M.S. degrees in telecommunications engineering from the University of Seville (US), Spain, in 2005 and 2007 respectively. In 2004, he joined the Power Electronics Group, US, working in R\&D projects. Currently, he is a predoctoral researcher pursuiting his $\mathrm{PhD}$ degree in electronic engineering. His research interests include electronic power systems; Flexible AC Transmission Systems (FACTS); microgrids; distributed power generation and the integration of renewable energy sources.

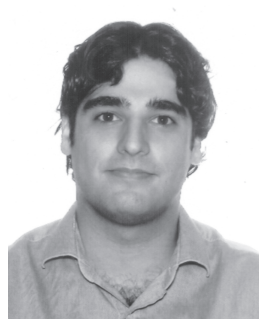

E. Dominguez (S'04, M'07) was born in Madrid, Spain, in 1976. He courses studies of telecommunication engineering from the University of Seville (US), Spain. He joined the Power Electronics Group in 1999, US, working in R\&D projects. He was the Research and Development Power Electronics Lab. Manager from 2005 to 2009 and currently he works as director of several research projects in the Power Electronics Group. His research interests include electronic power systems, hi performance hardware control systems and physical implementation of new power electronic converters applied to renewable energies.

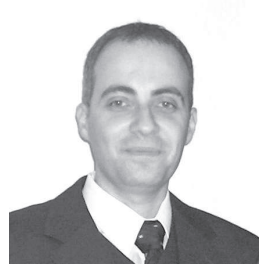

J.A. Sanchez was born in Moron, Spain, in 1974. He received the B.S. and M.S. degrees in industrial engineering from the University of Seville (US), Seville, Spain, in 2001 and 2004 respectively He is currently an Assistant Professor with the University of Seville, where he is working on his doctoral thesis on grid power quality. His research interests include power active filters, power control, and wind turbines. He is currently involved in related industrial projects, such as power conditioners for fuel cells and photovoltaic plants. 